Brief Report

\title{
Comparative Study of Curcumin and Its Hydrogenated Metabolites, Tetrahydrocurcumin, Hexahydrocurcumin, and Octahydrocurcumin, on Melanogenesis in B16F10 and MNT-1 Cells
}

\author{
Shilpi Goenka ${ }^{1, * \mathbb{D}}$ and Sanford R. Simon ${ }^{1,2,3}$ \\ 1 Department of Biomedical Engineering, Stony Brook University, Stony Brook, NY 11794-5281, USA; \\ sanford.simon@stonybrook.edu \\ 2 Department of Biochemistry and Cellular Biology, Stony Brook University, Stony Brook, NY 11794-5281, USA \\ 3 Department of Pathology, Stony Brook University, Stony Brook, NY 11794-5281, USA \\ * Correspondence: shilpi.goenka@stonybrook.edu
}

check for updates

Citation: Goenka, S.; Simon, S.R. Comparative Study of Curcumin and Its Hydrogenated Metabolites,

Tetrahydrocurcumin,

Hexahydrocurcumin, and

Octahydrocurcumin, on Melanogenesis in B16F10 and MNT-1 Cells. Cosmetics 2021, 8, 4. https://doi.org/10.3390/ cosmetics 8010004

Received: 12 December 2020 Accepted: 31 December 2020 Published: 4 January 2021

Publisher's Note: MDPI stays neutral with regard to jurisdictional clai$\mathrm{ms}$ in published maps and institutional affiliations.

Copyright: () 2021 by the authors. Licensee MDPI, Basel, Switzerland. This article is an open access article distributed under the terms and conditions of the Creative Commons Attribution (CC BY) license (https:// creativecommons.org/licenses/by/ $4.0 /)$.

\begin{abstract}
Curcumin, a bioactive from Curcuma longa, has been shown to possess anti-melanogenic activity previously; however, the effects of its hydrogenated metabolites (HMs) - Tetrahydrocurcumin (THC), Hexahydrocurcumin (HHC), and Octahydrocurcumin ( $\mathrm{OHC}$ — - on melanogenesis have not been sufficiently explored. We have studied and compared three HMs (THC, HHC, and OHC) with the parent compound, curcumin (PC), on melanin synthesis in B16F10 mouse and MNT-1 human melanoma cells. Our results demonstrated that all the HMs were nontoxic over the concentration range $5-40 \mu \mathrm{M}$, while PC was nontoxic at $5 \mu \mathrm{M}$ but induced toxicity at 20 and $40 \mu \mathrm{M}$ in B16F10 cells. All three HMs enhanced melanin synthesis, while PC $(5 \mu \mathrm{M})$ inhibited it. THC ( $40 \mu \mathrm{M})$ significantly stimulated melanin synthesis to a greater degree than HHC and OHC in both B16F10 and MNT-1 cells; the order of melanogenesis stimulation was $\mathrm{THC}=\mathrm{OHC}>\mathrm{HHC}$ in B16F10 mouse cells, while it was THC > HHC > OHC in MNT-1 cells. HMs stimulated melanogenesis by pathways not involving tyrosinase, as neither the intracellular tyrosinase activity nor the protein levels of tyrosinase were affected. In addition, mushroom tyrosinase activity, using L-Dihydroxyphenylalanine (L-DOPA) as the substrate, showed no direct effects of HMs. In summary, our results demonstrate that the HMs enhanced melanogenesis, which establishes that the hydrogenation of the heptadiene moiety of curcumin leads to a loss of its anti-melanogenic activity and instead results in the stimulation of melanogenesis. This stimulation is not further enhanced upon hydrogenation of the $\beta$-diketone, which was noted in MNT-1 cells, although the correlation to the number of keto groups differed in B16F10 cells where HHC was the weakest stimulator of melanogenesis. Collectively, THC with both keto groups intact is the best stimulator. Moreover, our results also validate that the electrophilicity of curcumin is necessary for its anti-melanogenic activity, as the non-electrophilic HMs did not inhibit melanogenesis. Furthermore, our results suggest that THC might hold promise as a stimulator of melanogenesis for treatment of hypopigmentation disorders and anti-graying therapies. Future studies to probe the molecular signaling mechanisms and test whether the pro-melanogenic activity of HMs is retained in primary human melanocytes are warranted.
\end{abstract}

Keywords: melanogenesis; tetrahydrocurcumin; hexahydrocurcumin; octahydrocurcumin; curcumin; heptadiene moiety; $\beta$-diketone

\section{Introduction}

Melanin is a polymeric pigment synthesized within melanosomes by melanocytes, cells derived from the neural crest, and it confers a host of protective biological benefits ranging from UV photoprotection [1] to free-radical chelation [2] and immune regulation [3]. The synthesis of melanin within melanosomes is primarily regulated by 
the rate-limiting enzyme tyrosinase which catalyzes the conversion of L-Tyrosine to LDihydroxyphenylalanine (L-DOPA) and undergoes further oxidation to the quinone, Ldopaquinone, which is then polymerized to melanin [4]. The overproduction of melanin leads to hyperpigmentation, which manifests as skin disorders such as melasma, freckles, and post-inflammatory hyperpigmentation (PIH) [5], while an underproduction of melanin leads to hypopigmentation disorders such as vitiligo and leukoderma [6,7]. These disorders lead to uneven skin pigmentation, which may have a profound psychosocial impact in individuals; hence, there is a growing need for the identification of novel compounds that can control pigmentation disorders. Several natural compounds suppress melanogenesis by inhibiting the activity of the enzyme tyrosinase; commercial skin-whitening agents include tyrosinase inhibitors such as kojic acid, arbutin, and hydroquinone. However, due to toxicological effects associated with their use [8,9], efforts have been directed toward the identification of natural compounds devoid of such toxicity.

Curcumin, a yellow polyphenolic derivative of ferulic acid obtained from turmeric rhizome (Curcuma Longa) and well-known for its broad spectrum of pharmacological activities, has been shown to inhibit melanogenesis in several earlier reports [10-14]. Reduction in vivo or catalytic hydrogenation in vitro of curcumin results in the formation of the metabolites-Tetrahydrocurcumin (THC), Hexahydrocurcumin (HHC), and Octahydrocurcumin (OHC) [15] (Figure 1). THC is a colorless metabolite of curcumin in which the two double bonds of the heptadiene moiety have been hydrogenated. While hydrogenation of the two double bonds alone in the heptadiene moiety in THC diminishes the intense yellow color of curcumin, studies reported that the biological properties of this derivative are also altered; THC has demonstrated superior antioxidative activities compared to curcumin, which are attributable to the retention of its $\beta$-diketone moiety $[16,17]$. THC exhibited wound-healing properties, enhanced synthesis of extracellular matrix [18], and exhibited anti-inflammatory activity in macrophages [19]. THC has also been shown to have neuroprotective effects in hippocampal HT22 cells [20] and a rat spinal cord injury model [21] as well as exert anti-diabetic effects [22] and anti-adipogenic effects [23]. The therapeutic efficacy of THC for cancer prevention has also been reviewed previously [24].

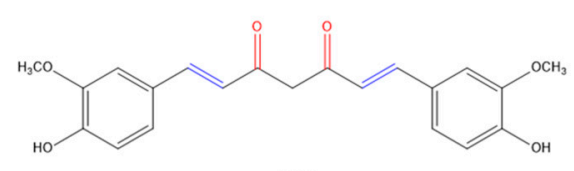

PC

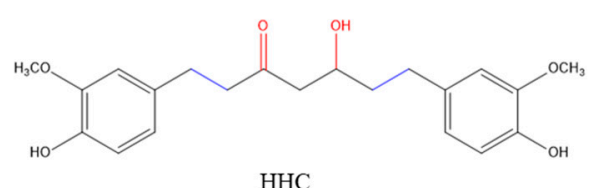

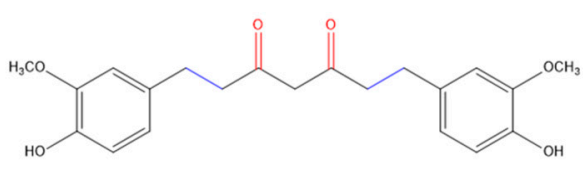

THC

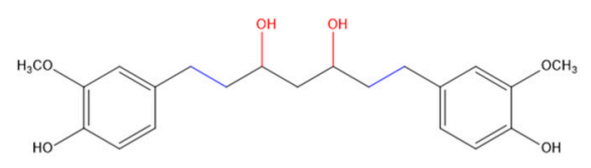

$\mathrm{OHC}$

Figure 1. Chemical structures of the parent compound, curcumin (PC) and its hydrogenated metabolites (HMs): Tetrahydrocurcumin (THC), Hexahydrocurcumin (HHC) and Octahydrocurcumin (OHC).

$\mathrm{HHC}$ is a cyclooxygenase 2 (COX-2) inhibitor that showed better anticancer effects in combination with 5-fluorouranil in colon cancer [25]. Several other studies have documented that HHC showed vasorelaxant effects [26], anti-angiogenic effects [27], and anti-atherosclerogenic effects by inhibiting platelet aggregation [28]. Furthermore, HHC alleviated brain damage in rats after cerebral ischemia/reperfusion injury [29]. OHC is the final hydrogenated metabolite (HM) of curcumin and has been shown to exert better antitumor efficacy than curcumin [30]. The antioxidant activity of the hydrogenated derivatives has been shown to be higher than that of curcumin in a previous study [31]. Additionally, OHC and THC were shown to be superior to curcumin in suppressing COX-2 expression and nuclear factor- $\mathrm{kB}(\mathrm{NF}-\mathrm{kB})$ pathways in a mouse paw edema model [32]. To the best of our knowledge, there has been no study on the effects of THC, HHC, and OHC on melanogenesis in cell cultures or their comparison 
with the parent compound curcumin. Hence, in this work, we tested and compared the HMs, THC, HHC, and OHC with PC on melanogenesis in vitro using B16F10 mouse melanoma cells and MNT-1 human melanoma cells.

\section{Results}

\subsection{Effects of Compounds on Cell Viability in B16F10 Cells}

We first tested the three HMs (THC, HHC, and $\mathrm{OHC}$ ) as well as PC for cytotoxicity to B16F10 mouse melanoma cells over a duration of $72 \mathrm{~h}$. Our results showed that the compounds THC, $\mathrm{HHC}$, and $\mathrm{OHC}$ were nontoxic over the concentration range 5-40 $\mu \mathrm{M}$ (Figure 2A), while PC induced significant cytotoxicity at higher concentrations; the mean cell viability was $20.24 \%$ for PC at $20 \mu \mathrm{M}$ (which was also significantly lower than PC at $5 \mu \mathrm{M}$ ) and $16.64 \%$ at $40 \mu \mathrm{M}$ (Figure $2 \mathrm{~B}$ ). Hence, we selected the HMs (5-40 $\mu \mathrm{M})$ and PC $(5 \mu \mathrm{M})$ in subsequent experiments.

A

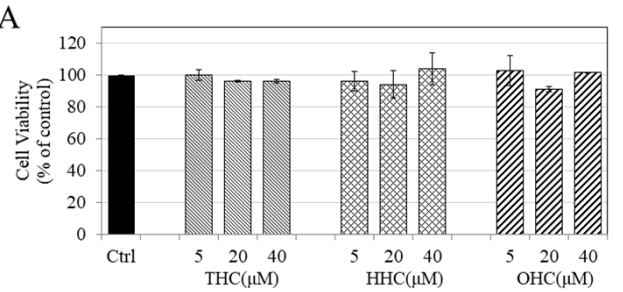

$\mathrm{B}$

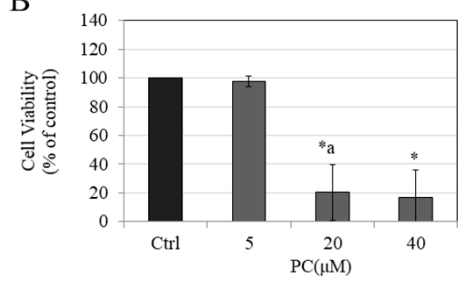

C

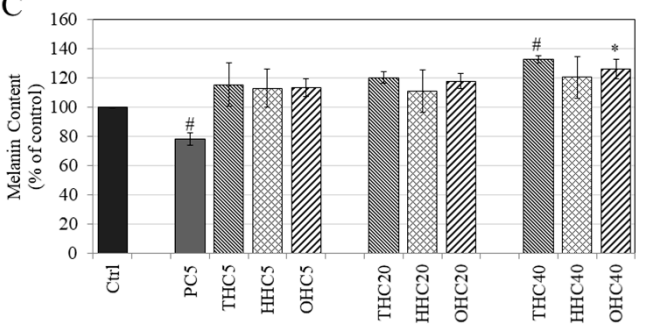

$\mathrm{E}$

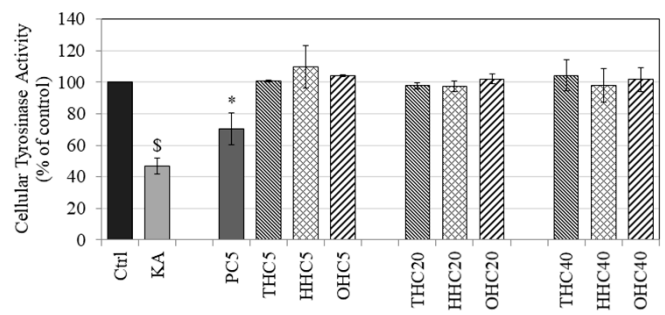

$\mathrm{D}$
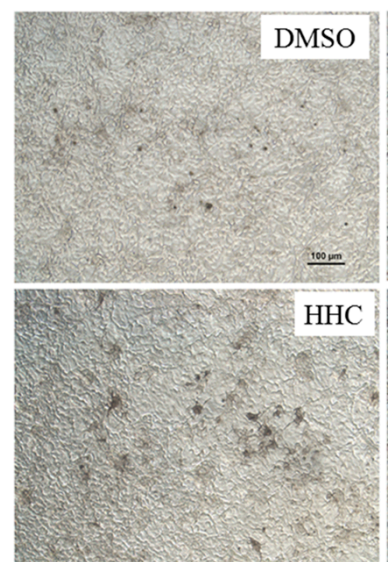

$\mathrm{HC}$
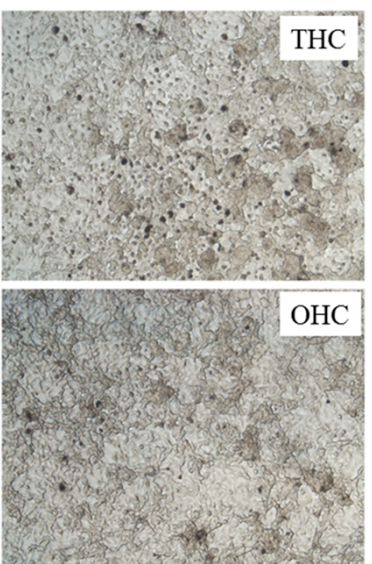

Figure 2. Viability of B16F10 mouse melanoma cells treated with (A) THC, HHC, OHC and; (B) PC for 3 d over a concentration range (5-40 $\mu \mathrm{M}$ ) measured using Alamar Blue assay; (One-way ANOVA followed by Tukey's test; * $p<0.05$ vs. Ctrl; letter a $-p<0.05$ vs. PC5; Data are mean \pm SD of at least two independent experiments); (C) Melanin content in B16F10 cells treated with PC and HMs for $3 \mathrm{~d} ;\left(^{*} p<0.05\right.$ and $\# p<0.001$ vs. Ctrl; One-way ANOVA with Tukey's test; the numbers with compounds in legends refer to concentrations in $\mu \mathrm{M}$; Data are pooled from at least two independent experiments); (D) Representative images of B16F10 cells treated with vehicle (0.4\% DMSO) or with HMs (THC, HHC, OHC) at $40 \mu \mathrm{M}$; scale bar is $100 \mu \mathrm{m}$; (E) Tyrosinase activity in B16F10 cells treated with PC and HMs for $3 \mathrm{~d}$ with kojic acid (KA) $(500 \mu \mathrm{M})$ used as a positive control; ( ${ }^{*} p<0.05$ vs. Ctrl; $\$ p<0.001$ vs. Ctrl; One-way ANOVA with Tukey's test; Data are means \pm SD of at least two independent experiments).

\subsection{Effects of Compounds on Melanin Synthesis in B16F10 Cells}

PC $(5 \mu \mathrm{M})$ significantly inhibited melanin synthesis by $21.76 \%$, while the HMs had an opposite effect and stimulated melanin synthesis (Figure 2C). All the HMs stimulated melanin synthesis by similar amounts at $5 \mu \mathrm{M}(14 \%$ increase by all $\mathrm{HMs})$; at $20 \mu \mathrm{M}$, melanin synthesis was further increased (THC $-20.19 \%$; HHC $-10.64 \%$, OHC $-17.78 \%$ ). These increases were not significantly different among the three metabolites and did 
not show significance as compared to control. However, at the highest dose of $40 \mu \mathrm{M}$, THC significantly stimulated melanin synthesis by $32.67 \%(p<0.01)$, while HHC only stimulated melanin synthesis by $20.42 \%(p>0.05)$ and OHC significantly stimulated melanin synthesis by $25.93 \%(p<0.05)$. The microscopic images of B16 cells showed no alterations in cellular morphology after treatment with the three HMs at $40 \mu \mathrm{M}$ (Figure 2D); an increased production of melanin granules within cells in THC and OHC groups was observed as compared to control, which was correlated to the quantitative results. Overall, the order of stimulation of melanin biosynthesis was $\mathrm{THC}=\mathrm{OHC}>\mathrm{HHC}$.

\subsection{Effects of Compounds on Intracellular Tyrosinase Activity in B16F10 Cells}

None of the HMs affected tyrosinase activity at any concentration, while PC $(5 \mu \mathrm{M})$ significantly inhibited tyrosinase activity by $29.58 \%$ as compared to control (Figure 2E), indicating that the hydrogenation of the heptadiene moiety of curcumin abolishes its anti-tyrosinase activity. In addition, these results also suggest that the mechanism of enhancement of melanin synthesis by HMs is unrelated to tyrosinase activity.

\subsection{Effects of Compounds on L-DOPA and L-Tyrosine Oxidation in a Cell-Free System}

We next assessed if the pro-melanogenic activity of HMs could be explained, at least in part, by a direct effect on mushroom tyrosinase enzyme in a cell-free system. Our results showed that all the HMs (THC, HHC, and OHC) unexpectedly inhibited monophenolase activity of the purified mushroom enzyme as compared to control in a dose-dependent manner, while PC $(5 \mu \mathrm{M})$ did not affect monophenolase activity (Figure 3A). At the lowest concentration of $5 \mu \mathrm{M}$, only HHC showed a significant inhibition (19.94\%); while HHC, along with THC and OHC, showed significant inhibition at $20 \mu \mathrm{M}$, with inhibition of $29.70 \%, 22.99 \%$, and $29.77 \%(p<0.01)$ for THC, HHC, and OHC, respectively. All the three compounds showed further inhibition at $40 \mu \mathrm{M}$ with inhibition of $61.99 \%, 41.10 \%$, and $45.10 \%$ for THC, HHC, and OHC, respectively. Notably, inhibition by THC $(40 \mu \mathrm{M})$ was significantly greater than that from $\mathrm{HHC}$ and $\mathrm{OHC}$ at $40 \mu \mathrm{M}$.

A

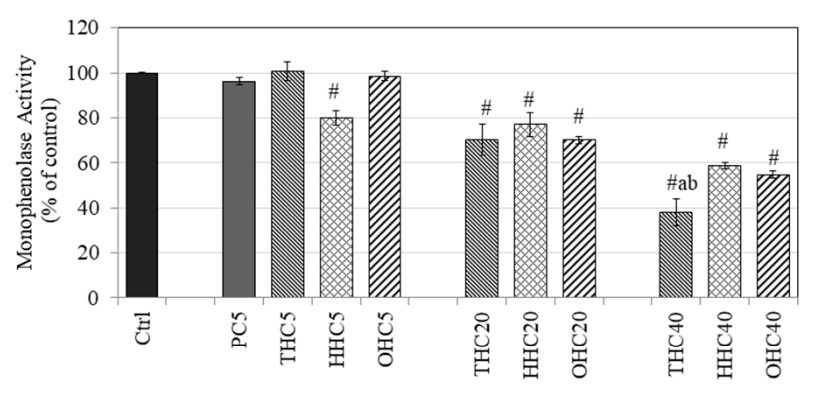

B

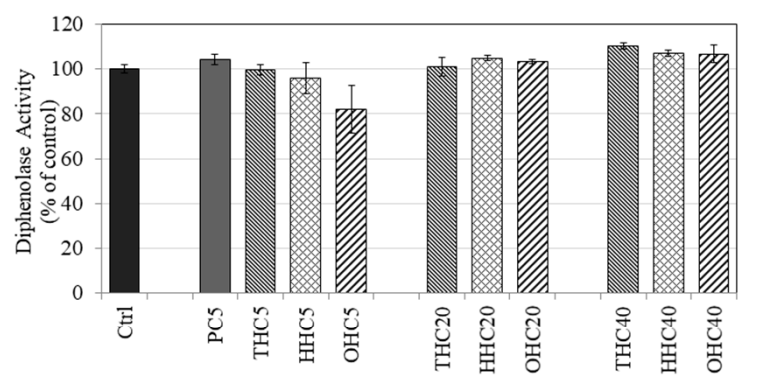

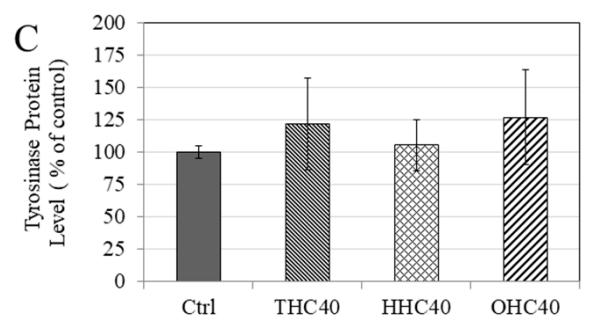

Figure 3. Effect of PC, THC, HHC, and OHC on (A) monophenolase activity and (B) diphenolase activity of mushroom tyrosinase; (\# $p<0.001$ vs. Ctrl; letter $\mathrm{a}-p<0.001$ vs. HHC40; letter $\mathrm{b}-p<0.01$ vs. OHC40; One-way ANOVA followed by Tukey's test); (C) Tyrosinase protein levels in B16F10 cells treated with $40 \mu \mathrm{M}$ of THC, HHC, and OHC for $3 \mathrm{~d}$ and protein levels were measured by ELISA; All data is mean \pm SD of triplicates.

Our results on diphenolase activity showed that neither THC, HHC, OHC, nor PC $(5 \mu \mathrm{M})$ had any effect on the diphenolase activity of mushroom tyrosinase at any con- 
centration (Figure 3B). Overall, the results suggested that the pro-melanogenic effect of HMs on mammalian cells is not likely to be attributed to a direct effect on any step of tyrosinase-catalyzed reaction.

\subsection{Effects of Compounds on Tyrosinase Protein Expression in B16F10 Cells}

The HMs (THC, HHC, and $\mathrm{OHC}$ at $40 \mu \mathrm{M}$ ) were evaluated to test whether their pro-melanogenic activity might arise, at least partially, from an increase in the expression of tyrosinase protein. Our results showed that none of the HMs (THC, HHC, and $\mathrm{OHC}$ ) had any significant effect on tyrosinase protein levels in B16F10 cells (Figure 3C). Altogether, these results suggest that the pro-melanogenic activity of HMs cannot be ascribed to expression of tyrosinase.

\subsection{Effects of Compounds on Viability in MNT-1 Cells}

The HMs were next evaluated for cytotoxicity to MNT-1 human melanoma cells; PC was included for comparison. Our results revealed that all the three HMs (THC, HHC, and $\mathrm{OHC}$ ) were nontoxic over the concentration range 5-40 $\mu \mathrm{M}$, while PC was nontoxic only at $5 \mu \mathrm{M}$ (Figure 4A). Hence, these concentrations were assayed for effects on melanogenesis.

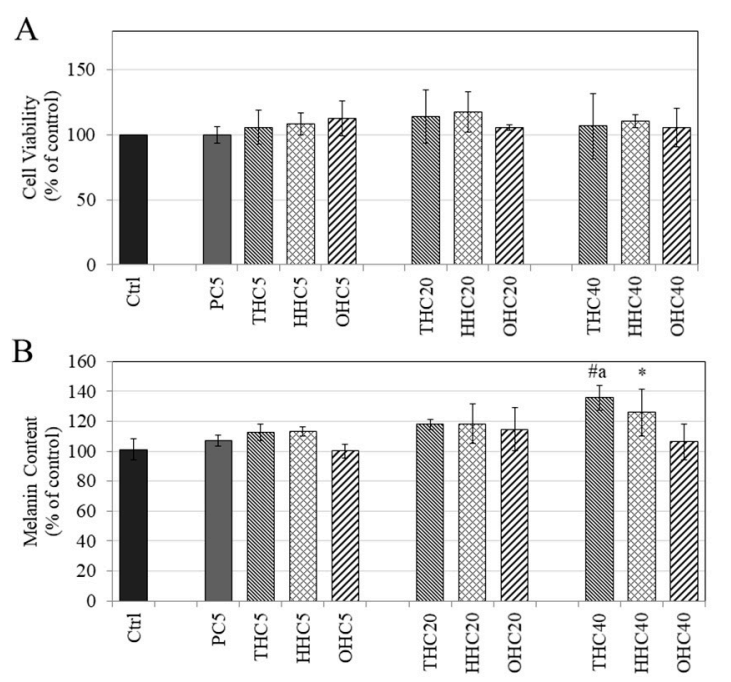

$\mathrm{D}$

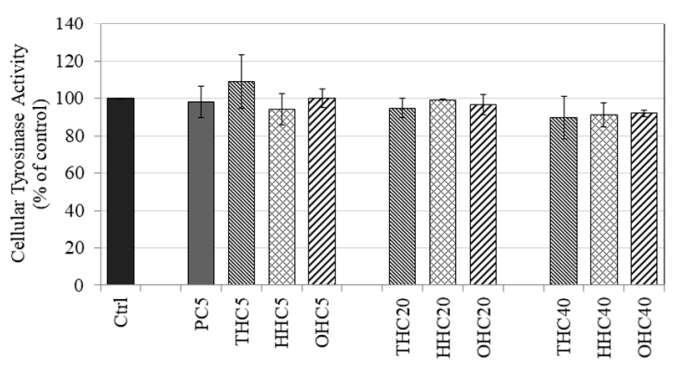

$\mathrm{C}$

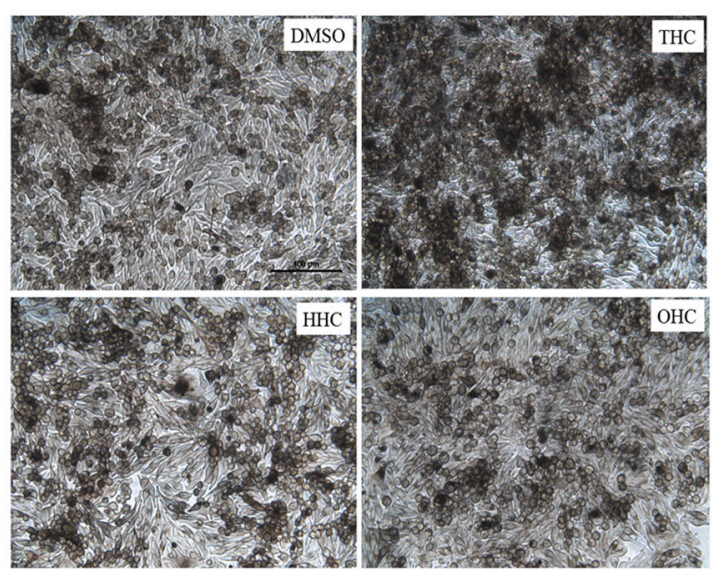

$\mathrm{E}$

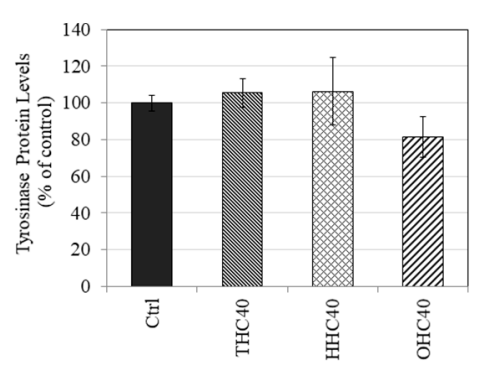

Figure 4. (A) Viability of MNT-1 human melanoma cells treated with compounds for $5 \mathrm{~d}$ over a concentration range $(5-40 \mu \mathrm{M})$ measured by Alamar Blue assay; $(p>0.05$; One-way ANOVA with Tukey's test; data are mean \pm SD of at least two independent experiments); (B) Melanin content in MNT-1 cells treated with PC and HMs for $5 \mathrm{~d}$; ( $p<0.05$ vs. Ctrl; $\# p<0.001$ vs. Ctrl; letter a- $p<0.01$ vs. HHC40; One-way ANOVA with Tukey's test; data are pooled from at least two independent experiments); (C) Representative images of MNT-1 cells treated with vehicle (0.4\% DMSO) or with HMs at $40 \mu \mathrm{M}$; scale bar is 100 microns; (D) Tyrosinase activity in MNT- 1 cells treated with PC and HMs for $5 \mathrm{~d}$; $(p>0.05$; One-way ANOVA with Tukey's test; data are means \pm SD of at least two independent experiments); (E) Tyrosinase protein levels in MNT-1 cells treated with $40 \mu \mathrm{M}$ of THC, HHC, and OHC for $5 \mathrm{~d}$ and protein levels were measured by ELISA. (One-way ANOVA with Tukey's test; no significance was obtained $(p>0.05)$; data is mean \pm SD of triplicate determinations). 


\subsection{Effects of Compounds on Melanin Synthesis in MNT-1 Cells}

Our results on the effects of HMs on melanin production in MNT-1 cells showed a dose-dependent increase in intracellular melanin content with THC being the most potent amongst all HMs. THC $(40 \mu \mathrm{M})$ significantly stimulated melanin levels by $35.71 \%$ $(p<0.001)$ and HHC $(40 \mu \mathrm{M})$ significantly stimulated melanin levels by $25.87 \%(p<0.05)$, while $\mathrm{OHC}(40 \mu \mathrm{M})$ did not affect melanin content (Figure $4 \mathrm{~B})$. The increase in melanin content by THC $(40 \mu \mathrm{M})$ was also significantly higher $(p<0.01)$ than OHC $(40 \mu \mathrm{M})$. PC $(5 \mu \mathrm{M})$ was inactive at inhibiting melanogenesis. The micrographs of MNT-1 cells treated with HMs $(40 \mu \mathrm{M})$ showed a visibly higher content of melanin pigment in THC $(40 \mu \mathrm{M})$ as compared to the other two HMs as well as control (Figure 4C). Overall, the order of melanogenesis stimulation was THC $>\mathrm{HHC}>\mathrm{OHC}$. These results agree with our earlier results with B16F10 mouse melanoma cells where THC showed greater pro-melanogenic activity compared to $\mathrm{HHC}$ and $\mathrm{OHC}$.

\subsection{Effects of Compounds on Intracellular Tyrosinase Activity and Tyrosinase Protein Expression in MNT-1 Cells}

Our results showed that all the HMs (THC, HHC, and OHC) in the tested concentration range had no effect on intracellular tyrosinase activity (Figure 4D) in MNT-1 cells. Moreover, the HMs (THC, HHC, and $\mathrm{OHC}$ all at $40 \mu \mathrm{M}$ ) were evaluated to test if they might increase tyrosinase protein levels, which might explain their melanogenesis stimulatory activity, but there was no change in protein levels compared to control; a trend for reduction was noted for OHC, which did not reach significance (Figure 4E). Collectively, our data demonstrate that the stimulation of melanogenesis by HMs is not mediated by changes in tyrosinase activity or tyrosinase protein levels but might involve other pathways.

\section{Discussion}

Our results demonstrate these salient findings: (i) all the HMs (THC, HHC, and OHC) stimulated melanogenesis in contrast to PC, which inhibited melanogenesis; (ii) the heptadiene moiety in the parent compound curcumin appears to be critical for anti-melanogenic activity, since hydrogenation of the heptadiene moiety leads to stimulation rather than the inhibition of melanogenesis; (iii) the successive hydrogenation of $\beta$-diketone does not lead to a further stimulation of melanogenesis. Our results further highlighted that the heptadiene moiety in the curcumin structure, which imparts electrophilicity to curcumin and aids in conjugation to enhance tautomerism, is critical for anti-melanogenic activity but also contributes to cytotoxicity, since the three HMs did not exhibit any cytotoxicity. Our dissection of the role of the heptadiene moiety in HMs showed that the potency of enhancement of melanin levels in MNT-1 cells follows the order THC > HHC > OHC, which coincides with the order of successive hydrogenation of $\beta$-diketone: THC has both keto groups intact, $\mathrm{HHC}$ has one keto group reduced, and $\mathrm{OHC}$ has both keto groups reduced. The order of stimulation of melanogenesis was THC $=\mathrm{OHC}>\mathrm{HHC}$ in B16F10 mouse melanoma cells, which was different from that of MNT-1 human melanoma cells where the order was THC > HHC > OHC. It is worthwhile to note that the effect of the degree of hydrogenation of $\beta$-diketone did not follow a linear correlation to the levels of melanin synthesis in B16F10 cells, where HHC seemed to be the weakest stimulator of melanogenesis, so that only one keto group remaining seems to be the key to minimize the effect of stimulation of melanogenesis. We speculate that these divergent effects might be ascribed to the differences in the catalytic properties of human and mouse melanogenic enzymes that have been noted previously $[33,34]$, which might differentially regulate the effects of HMs on them. Nonetheless, as the further application of the HMs would be most likely for human use, our results, and the order of correlation with the successive hydrogenation in MNT-1 cells provides credence to our findings.

Currently, there are no reports on the effects of $\mathrm{HHC}$ and $\mathrm{OHC}$ on melanogenesis, while the effects of THC are conflicting with findings of both inhibition and stimulation of melanogenesis. For example, two studies documented the anti-melanogenic activity of 
low and high dose THC in hormone-stimulated B16F10 cells $[35,36]$, while a mixture of tetrahydrocurcuminoids (not pure THC; Sabiwhite ${ }^{\mathrm{TM}}, 95 \%$ THC) at $0.25 \%$ has been in commercial use for skin-whitening. Another report documented the pro-melanogenic activity of THC in vivo, where a cream formulated with a mixture of tetrahydrocurcuminoids in conjunction with UVB phototherapy was shown to stimulate skin pigmentation in vitiligo patients [18]. In addition, a patent has been issued on the use of tetrahydrocurcuminoids for self-tanning [37]. Our in vitro results of the stimulation of melanogenesis by THC $(40 \mu \mathrm{M})$ contrast with findings of the study [36] where THC at concentrations of $10 \mu \mathrm{g} / \mathrm{mL}$ (equivalent to $26 \mu \mathrm{M}$ ) and higher inhibited melanin synthesis in hormone-stimulated B16F10 cells as well another study where a much lower THC concentration of $0.1 \mu \mathrm{g} / \mathrm{mL}(\approx 0.26 \mu \mathrm{M})$ inhibited melanin synthesis in hormone-stimulated B16F10 cells [35]. Overall, our in vitro results agree with in vivo findings of the stimulation of melanogenesis by THC $[18,37]$.

In this work, our primary focus was to test and compare the three HMs to PC, which was used as a reference compound. Although there are no reports of PC on melanogenesis yet, a crude mixture of curcumin (containing 70\% PC) previously demonstrated anti-melanogenic activity in B16F10 cells [38]. We selected PC (or curcumin I as it is also called, to distinguish it from its further demethoxylated analogs), instead of the crude mixture of curcuminoids to better elucidate the structure-activity relationships (SAR), since we sought to compare it with its purified HMs. We found that PC inhibited melanin synthesis at $5 \mu \mathrm{M}$ but induced cytotoxicity at higher concentrations in B16F10 cells, while it was inactive at melanogenesis at the same concentration in MNT-1 cells with cytotoxicity at higher concentrations of $20 \mu \mathrm{M}$ and $40 \mu \mathrm{M}$ (Figure S1). The reasons for the discrepancy between the cell lines could be ascribed to differences in sensitivity of the compound to two different cell lines and inherent speciesspecific differences. In addition, it could be explained by the higher basal pigmentation of MNT-1 cells than in B16F10 cells; compounds which inhibit melanin synthesis in B16F10 might fail to show activity at same concentrations in MNT-1 cells. Nevertheless, our results of the cytotoxicity profile of PC in both cells are consistent. The enone moiety of curcumin is a typical Michael-addition acceptor and can react with biologically relevant nucleophilic groups such as the sulfhydryl groups present in glutathione as well as proteins involved in melanogenesis. Hence, we studied the effects of L-cysteine on PC toxicity in B16F10 cells, and our results showed that L-cysteine lowered the cytotoxicity of PC indicative of the involvement of Michael-type addition reactions (Figure S2).

Unlike the diphenolase activity, the monophenolase activity of tyrosinase is characterized by a lag period which has been shown to be lengthened by certain tyrosinase inhibitors [39]. In the present study, we did not evaluate if the HMs might also have an effect on the lag time in our assays of monophenolase activity. Our results of cell-free mushroom tyrosinase activity showed a significant inhibition of the monophenolase activity by HMs, while the diphenolase activity was unaffected, which is suggestive of the capacity of HMs to selectively inhibit the first step of enzyme catalysis. However, our cell culture studies indicated that these compounds were in fact stimulators of melanogenesis. Similar findings were also noted with the compounds methyl cinnamate (structurally similar to curcumin) and methyl 3-phenylpropionate, where authors noted that the latter compound inhibited monophenolase activity with no effects on diphenolase activity but stimulated melanogenesis in cell cultures [40]. Another study also reported a similar observation in which the authors noted the inhibition of mushroom tyrosinase activity but the stimulation of melanogenesis in B16F10 cells by plasma-activated compounds [41]. This discrepancy can be explained by the differences between mushroom tyrosinase and human tyrosinase [42]; it has been reported that results from the mushroom tyrosinase assay may not be a true indicator of response from cellular melanin levels [43]. The enzyme TRP-2 (also called as dopachrome tautomerase; DCT) catalyzes the tautomerization of Dopachrome to 5,6-dihydroxyindole-2-carboxylic acid (DHICA) while 5,6-dihydroxyindole (DHI) is produced non-enzymatically in mammals [44]. The oxidative polymerization of both DHI and DHICA generates the natural eumelanin pigment found in mammals. One possibility that might explain, at least in part, the pro-melanogenic effect of HMs is that they might 
bind to melanin pigment during dopaquinone and DHI polymerization (Raper-Mason pathway) via their hydroxy or keto groups leading to the formation of a greater amount of dark pigment, which was detected in our spectrophotometric assays.

The role of melanosome $\mathrm{pH}$ in the regulation of melanin synthesis has been described previously, and compounds that increase melanosome $\mathrm{pH}$ can stimulate melanin synthesis $[45,46]$. We had previously reported on calebin-A, a curcuminoid analog, which suppressed melanin synthesis in B16F10 cells via the acidification of cell organelles without affecting the intracellular tyrosinase activity [47]. Another study [48] also reported a similar finding by a flavone hesperidin that suppressed melanin synthesis in human melanoma cells in the absence of effects on cellular tyrosinase activity but induced the acidification of melanosomes. We speculate that our findings of the stimulating effects of THC on melanogenesis in the absence of effects on cellular tyrosinase activity might be related to changes in the ionic equilibrium of melanocytes and $\mathrm{pH}$ or effects on protein expression of proton-dependent channels in melanocytes, which warrants further investigation.

Although the levels of stimulation of melanogenesis by HMs were moderate in B16F10 cells, in MNT-1 cells, the degree of activation of melanogenesis can be considered robust, since MNT-1 cells have a much higher melanin content than B16F10 cells yet were shown to demonstrate stimulation by HMs. The effects of THC, HHC, and OHC on both cells are outlined in Table S1. Nevertheless, further studies will be necessary before HMs could be definitively touted as stimulators of melanogenesis.

\section{Materials and Methods}

\subsection{Materials}

Tetrahydrocurcumin (THC; $>95 \%$ purity), Hexahydrocurcumin (HHC; $>95 \%$ purity), and Octahydrocurcumin (OHC; $>98 \%$ purity) were purchased from Chemscene Inc. (Monmouth Junction, NJ, USA). Curcumin (PC; 99\% purity) was purchased from Selleck Chemicals (Houston, TX, USA). Mushroom tyrosinase, kojic acid (KA), L-Tyrosine, and L-dihydroxyphenylalanine (L-DOPA) were purchased from Sigma-Aldrich (St. Louis, MO, USA). Alamar blue reagent (Cat\# DAL1025) and bicinchoninic acid (BCA) protein assay kit (Thermo Scientific ${ }^{\mathrm{TM}}$ Pierce ${ }^{\mathrm{TM}}$ ) was purchased from Thermo Fisher Scientific (Waltham, MA, USA).

\subsection{Cell Culture}

B16F10 mouse melanoma cells were obtained from the American Type Culture Collection (ATCC; Manassas, VA, USA) and cultured using Dulbecco's Modified Eagle's Medium (DMEM) supplemented with 10\% heat-inactivated fetal bovine serum (HI-FBS; R\&D Systems, Minneapolis, MN, USA) and 1\% antibiotics (penicillin-streptomycin). MNT-1 human melanoma cells were obtained as a kind gift from Dr. Michael Marks (University of Pennsylvania, Philadelphia, PA, USA) and cultured using DMEM supplemented with $18 \%$ HI-FBS, 1\% Minimum Essential Medium (MEM; Gibco), 1\% antibiotics, and 10\% AIM-V medium (Invitrogen, Waltham, MA, USA). All cells were cultured at $37^{\circ} \mathrm{C}$ in a humidified atmosphere in a $95 \%$ air- $5 \% \mathrm{CO}_{2}$ incubator.

\subsection{Testing in B16F10 and MNT-1 Cells \\ 4.3.1. Cytotoxicity Assay}

The compounds were first tested for cytotoxicity to B16F10 cells using Alamar Blue dye cytotoxicity assay before testing them in melanogenesis assays. Briefly, B16F10 cells $\left(5 \times 10^{3}\right.$ cells/well) were plated in 96-well plates for $24 \mathrm{~h}$ followed by the addition of compounds and further incubated for $72 \mathrm{~h}$. The final DMSO concentration in all groups including the control was $0.4 \%$. After the treatments, the medium was replaced by $100 \mu \mathrm{L}$ of fresh medium with $10 \mu \mathrm{L}$ of Alamar Blue dye and incubated for $2 \mathrm{~h}$, after which the absorbance was read at $570 \mathrm{~nm}$ and $600 \mathrm{~nm}$ as a reference wavelength, using a Versamax ${ }^{\circledR}$ microplate reader. The method adopted for the calculation of cellular viability by Ala- 
mar blue dye has been validated in previous reports $[49,50]$ and has been listed under supplementary methods.

MNT-1 cells were cultured in 96-well plates $\left(1 \times 10^{4}\right.$ cells/well) and compounds were added the next day, and cells were cultured for a period of $5 \mathrm{~d}$ with the compounds replenished on the third day of culture. At the end of treatments, the viability was measured by Alamar Blue assay similar to the method outlined above for B16F10 cells.

\subsubsection{Melanogenesis Assay}

B16F10 cells $\left(5 \times 10^{4}\right.$ cells/well) were cultured in 12-well plates for $24 \mathrm{~h}$ followed by the addition of compounds and further cultured for $72 \mathrm{~h}$. At the end of the treatments, the cells were detached using TrypLE (TrypLE Express,1X, Gibco), washed in phosphate buffered saline (PBS), and $250 \mu \mathrm{L}$ of $1 \mathrm{~N} \mathrm{NaOH}$ was added and heated to $70{ }^{\circ} \mathrm{C}$ for $30 \mathrm{~min}$ to solubilize melanin. Aliquots were transferred to a 96 -well plate, and the absorbance was read at $475 \mathrm{~nm}$ using a microplate reader, and a portion of the lysate was used to evaluate the total protein content using BCA assay. The absorbance was normalized to the total protein contents and reported as relative melanin levels as a percentage of the control.

We tested the effects of compounds on melanin synthesis in MNT-1 cells using a method similar to the one outlined above for B16F10 cells. Briefly, MNT-1 cells were seeded in 6-well plates for $24 \mathrm{~h}$ and treated with compounds for $5 \mathrm{~d}$. After the treatments, cells were harvested, washed in PBS, and solubilized in $450 \mu \mathrm{L} 1 \mathrm{~N} \mathrm{NaOH}$ at $70{ }^{\circ} \mathrm{C}$, and the absorbance of aliquots $(200 \mu \mathrm{L})$ was read at $475 \mathrm{~nm}$ and normalized to the total protein content. The relative melanin levels were expressed as percentage of control.

\subsubsection{Intracellular Tyrosinase Activity}

B16F10 cells $\left(2 \times 10^{4}\right.$ cells / well $)$ were cultured in 24 -well plates for $24 \mathrm{~h}$ followed by the addition of compounds and further incubated for $72 \mathrm{~h}$. At the end of treatments, cells were detached, and cell pellets were washed in PBS and lysed using lysis buffer containing $1 \%$ Nonidet-P 40 (NP-40). Lysates $(50 \mu \mathrm{L})$ were aliquoted in a 96 -well microplate, and $100 \mu \mathrm{L}$ of $3 \mathrm{mM}$ L-DOPA was added. The absorbance was measured at $475 \mathrm{~nm}$ in the kinetic mode every $30 \mathrm{sec}$ for $30 \mathrm{~min}$ at $30^{\circ} \mathrm{C}$ using a microplate reader. The percentage of tyrosinase activity was calculated from the slope of the linear range of the velocities of inhibition and was normalized to the total protein contents.

MNT-1 cells $\left(1.2 \times 10^{5}\right.$ cells/well $)$ were seeded in 12-well plates and treated with the compounds the next day, and cultures were continued for a duration of $5 \mathrm{~d}$. At the end of treatments, the intracellular tyrosinase activity was assayed similar to the method outlined earlier for B16F10 cells.

\subsubsection{Tyrosinase Protein Levels}

B16F10 cells $\left(5 \times 10^{4}\right.$ cells/well) were cultured in 12-well plates for $24 \mathrm{~h}$ followed by the addition of compounds, and cultures were maintained for $72 \mathrm{~h}$. At the end of treatments, cells were lysed, and supernatants were collected and stored at $-20{ }^{\circ} \mathrm{C}$. For assaying tyrosinase protein levels, a sandwich-based ELISA kit (LSBio, Seattle, WA, USA) was run according to the manufacturer's instructions. The relative tyrosinase expression was evaluated by measurement of absorbance at $450 \mathrm{~nm}$, which was normalized to total protein contents and reported as percentage of the untreated control group.

MNT-1 cells were seeded in a 96-well plate and treated with compounds for $5 \mathrm{~d}$ and then analyzed for tyrosinase protein expression using a cell-based ELISA (Lifespan Biosciences Inc., Seattle, WA, USA) based on the manufacturer's instructions. The use of cell-based ELISA as a modified ELISA capable of detecting protein markers on cell surfaces with a higher sensitivity has been validated in previous reports [51,52]. Crystal violet stain was used to normalize the absorbance values to cell density in each well and relative levels of tyrosinase protein expression was reported as percentage of control. 


\subsection{Cell-Free Tyrosinase Activity Using L-TYR and L-DOPA Substrates}

In order to elucidate if the mechanism of melanogenesis stimulation by HMs might include a direct effect on tyrosinase enzyme activity, we tested the compounds with a purified mushroom tyrosinase using two substrates: L-TYR (monophenolase) and L-DOPA (diphenolase) based on the method reported in our earlier work [53]. For testing monophenolase activity, $80 \mu \mathrm{L}$ of compounds prepared in $0.05 \mathrm{M}$ sodium phosphate buffer were added to 96-well plates followed by the addition of $100 \mu \mathrm{L}$ of $1 \mathrm{mM} \mathrm{L-TYR}$ substrate. The reaction was initiated by adding $20 \mu \mathrm{L}$ of enzyme (final enzyme concentration was $12.5 \mu \mathrm{g} / \mathrm{mL}$ ) and monitored by measuring absorbance at $475 \mathrm{~nm}$ for $30 \mathrm{~min}$, using a microplate reader in kinetic mode. The slopes of the plots of absorbance vs. time were normalized to total protein content and expressed as percentage of control. For testing diphenolase activity, a similar method was used, except the substrate used was $100 \mu \mathrm{L}$ of $6 \mathrm{mM}$ L-DOPA and $20 \mu \mathrm{L}$ of enzyme (at final concentration of $3.5 \mu \mathrm{g} / \mathrm{mL}$ ). The slopes of the kinetic readings were calculated to determine and compare tyrosinase activity from the control.

\subsection{Statistical Analysis}

One-way analysis of variance (ANOVA) with Tukey's test or Dunnett's post-hoc test was run using GraphPad Prism software (version 4.0, GraphPad Software Inc, La Jolla, CA, USA). Differences were considered statistically significant at $p<0.05$. All data are reported as mean $\pm \mathrm{SD}$.

\section{Conclusions}

In conclusion, our results demonstrate a proof-of-principle for the critical role of the $\beta$-diketone moiety of curcumin in inhibiting melanogenesis, since its hydrogenation resulted in the enhancement of melanogenesis instead of inhibition. Furthermore, our results in MNT- 1 cells demonstrate that the successive hydrogenation of $\beta$-diketone does not lead to a further stimulation of melanogenesis. We also report the novel finding of pro-melanogenic activity of HMs of curcumin, with THC emerging as the best candidate for stimulating melanogenesis in B16F10 mouse melanoma cells and MNT-1 human melanoma cells, which is indicative of its promise as a pro-melanogenic compound for gray hair and for vitiligo therapy. THC, in contrast to the other two HMs (HHC and OHC), merits further investigation as a bioactive candidate for increasing melanin synthesis, and more in-depth studies on a mechanistic level and testing in primary human melanocytes are warranted for future work.

Supplementary Materials: The following are available online at https://www.mdpi.com/2079-9 284/8/1/4/s1. Figure S1: Viability of MNT-1 human melanoma cells treated with PC at various concentrations $(5-40 \mu \mathrm{M})$ for duration of $5 \mathrm{~d}$ tested by Alamar Blue assay; $\# p<0.001 \mathrm{vs.} \mathrm{control;}$ One-way ANOVA with Dunnett's test; Data are mean \pm SD of triplicate determinations; Figure S2: Viability of B16F10 mouse melanoma cells treated with PC $(10 \mu \mathrm{M})$ in the presence or absence of L-Cysteine (Cy) for duration of $3 \mathrm{~d}$ tested by Alamar Blue assay. Co-addition of L-cysteine (Cy) restores the cytotoxicity of $\mathrm{PC}$ indicating a role of the Michael reaction acceptor on the $\beta$-diketone bond; PC10 indicates PC at $10 \mu \mathrm{M}$; L-Cysteine (Cy) at $300 \mu \mathrm{M}$ and $600 \mu \mathrm{M}$ was added; (\#-p<0.001 vs. Ctrl; letter a $-p<0.001$ vs. PC10; One-way ANOVA with Tukey's test); Data is mean \pm SD of triplicate determinations. Table S1: Summary of the effects of THC, HHC and OHC on melanogenesis in both melanoma cells.

Author Contributions: S.G.: Conceptualization; investigation; formal analysis; original draft preparation, writing, editing; S.R.S.: resources; review. Both authors approved the final draft. All authors have read and agreed to the published version of the manuscript.

Funding: We gratefully acknowledge the partial support from the Center for Biotechnology (CFB), an Empire State Development Division of Science Technology and Innovation (NYSTAR) Center for Advanced Technology and partial corporate support from Biocogent, LLC (Stony Brook).

Institutional Review Board Statement: Not Applicable.

Informed Consent Statement: Not Applicable. 
Data Availability Statement: The data presented in this study are available on request from the corresponding author. The data are not publicly available due to the confidentiality of the sponsored research agreement.

Acknowledgments: The authors would like to thank Michael Marks, University of Pennsylvania, for graciously providing MNT-1 human melanoma cells.

Conflicts of Interest: The authors declare no conflict of interest.

$\begin{array}{ll}\text { Abbreviations } & \\ \text { SAR } & \text { Structure-Activity Relationship } \\ \text { PC } & \text { Pure Curcumin } \\ \text { HM } & \text { Hydrogenated Metabolite } \\ \text { THC } & \text { Tetrahydrocurcumin } \\ \text { HHC } & \text { Hexahydrocurcumin } \\ \text { OHC } & \text { Octahydrocurcumin } \\ \text { KA } & \text { Kojic Acid } \\ \text { DMEM } & \text { Dulbecco's Modified Eagle Medium } \\ \text { MEM } & \text { Minimum Essential Medium } \\ \text { L-DOPA } & \text { L-Dihydroxyphenylalanine } \\ \text { TYR } & \text { Tyrosinase } \\ \text { ANOVA } & \text { Analysis of Variance } \\ \text { HBSS } & \text { Hank's Balanced Salt Solution } \\ \text { HI-FBS } & \text { Heat-Inactivated Fetal Bovine Serum } \\ \text { ELISA } & \text { Enzyme-Linked Immunosorbent Assay }\end{array}$

\section{References}

1. Brenner, M.; Hearing, V.J. The protective role of melanin against UV damage in human skin. Photochem. Photobiol. 2008, 84, 539-549. [CrossRef] [PubMed]

2. Herrling, T.; Jung, K.; Fuchs, J. The role of melanin as protector against free radicals in skin and its role as free radical indicator in hair. Spectrochim. Acta Part A Mol. Biomol. Spectrosc. 2008, 69, 1429-1435. [CrossRef]

3. Hong, Y.; Song, B.; Chen, H.D.; Gao, X.H. Melanocytes and Skin Immunity. J. Investig. Dermatol. Symp. Proc. 2015, 17, 37-39. [CrossRef] [PubMed]

4. Hearing, V. Unraveling the melanocyte. Am. J. Hum. Genet. 1993, 52, 1. [PubMed]

5. Ortonne, J.-P.; Bissett, D.L. Latest insights into skin hyperpigmentation. J. Investig. Dermatol. Symp. Proc. 2008, 13, 10-14. [CrossRef] [PubMed]

6. Nicolaidou, E.; Katsambas, A.D. Pigmentation disorders: Hyperpigmentation and hypopigmentation. Clin. Dermatol. 2014, 32, 66-72. [CrossRef] [PubMed]

7. Braun-Falco, O.; Plewig, G.; Wolff, H.H.; Burgdorf, W.H. Disorders of melanin pigmentation. In Dermatology; Springer: Berlin/Heidelberg, Germany, 2000; pp. 1013-1042.

8. Draelos, Z.D. Skin lightening preparations and the hydroquinone controversy. Dermatol. Ther. 2007, 20, 308-313. [CrossRef]

9. García-Gavín, J.; González-Vilas, D.; Fernández-Redondo, V.; Toribio, J. Pigmented contact dermatitis due to kojic acid. A paradoxical side effect of a skin lightener. Contact Dermat. 2010, 62, 63-64. [CrossRef]

10. Jang, J.Y.; Lee, J.H.; Jeong, S.Y.; Chung, K.T.; Choi, Y.H.; Choi, B.T. Partially purified Curcuma longa inhibits alpha-melanocytestimulating hormone-stimulated melanogenesis through extracellular signal-regulated kinase or Akt activation-mediated signalling in B16F10 cells. Exp. Dermatol. 2009, 18, 689-694. [CrossRef]

11. Lee, J.H.; Jang, J.Y.; Park, C.; Kim, B.W.; Choi, Y.H.; Choi, B.T. Curcumin suppresses alpha-melanocyte stimulating hormonestimulated melanogenesis in B16F10 cells. Int. J. Mol. Med. 2010, 26, 101-106. [CrossRef]

12. Park, S.Y.; Jin, M.L.; Kim, Y.H.; Kim, Y.; Lee, S.J. Aromatic-turmerone inhibits alpha-MSH and IBMX-induced melanogenesis by inactivating CREB and MITF signaling pathways. Arch. Dermatol. Res. 2011, 303, 737-744. [CrossRef] [PubMed]

13. Hosoya, T.; Nakata, A.; Yamasaki, F.; Abas, F.; Shaari, K.; Lajis, N.H.; Morita, H. Curcumin-like diarylpentanoid analogues as melanogenesis inhibitors. J. Nat. Med.-Tokyo 2012, 66, 166-176. [CrossRef] [PubMed]

14. Mustarichie, R.; Levita, J.; Febriani, D. In-Silico Study of Curcumin, Demethoxycurcumin and Xanthorrizol as Skin Whitening Agents. World J. Pharm. Sci. 2013, 1, 72-80.

15. Gopi, S.; Jacob, J.; George, R. Kinetic studies on the hydrogenation of curcuminoids isolated from Curcuma Longa by LC/MS. Res. J. Chem. Sci. ISSN 2015, 2231, 606X.

16. Aggarwal, B.B.; Deb, L.; Prasad, S. Curcumin differs from tetrahydrocurcumin for molecular targets, signaling pathways and cellular responses. Molecules 2014, 20, 185-205. [CrossRef]

17. Sugiyama, Y.; Kawakishi, S.; Osawa, T. Involvement of the beta-diketone moiety in the antioxidative mechanism of tetrahydrocurcumin. Biochem. Pharmacol. 1996, 52, 519-525. [CrossRef] 
18. Asawanonda, P.; Klahan, S.O. Tetrahydrocurcuminoid cream plus targeted narrowband UVB phototherapy for vitiligo: A preliminary randomized controlled study. Photomed. Laser Surg. 2010, 28, 679-684. [CrossRef]

19. Zhao, F.; Gong, Y.; Hu, Y.; Lu, M.; Wang, J.; Dong, J.; Chen, D.; Chen, L.; Fu, F.; Qiu, F. Curcumin and its major metabolites inhibit the inflammatory response induced by lipopolysaccharide: Translocation of nuclear factor-kappaB as potential target. Mol. Med. Rep. 2015, 11, 3087-3093. [CrossRef]

20. Park, C.H.; Song, J.H.; Kim, S.N.; Lee, J.H.; Lee, H.J.; Kang, K.S.; Lim, H.H. Neuroprotective Effects of Tetrahydrocurcumin against Glutamate-Induced Oxidative Stress in Hippocampal HT22 Cells. Molecules 2019, 25, 144. [CrossRef]

21. Xi, J.; Luo, X.; Wang, Y.; Li, J.; Guo, L.; Wu, G.; Li, Q. Tetrahydrocurcumin protects against spinal cord injury and inhibits the oxidative stress response by regulating FOXO4 in model rats. Exp. Ther. Med. 2019, 18, 3681-3687. [CrossRef]

22. Yuan, T.; Yin, Z.; Yan, Z.; Hao, Q.; Zeng, J.; Li, L.; Zhao, J. Tetrahydrocurcumin ameliorates diabetes profiles of db/db mice by altering the composition of gut microbiota and up-regulating the expression of GLP-1 in the pancreas. Fitoterapia 2020, 146, 104665. [CrossRef] [PubMed]

23. Pan, M.H.; Chen, J.W.; Kong, Z.L.; Wu, J.C.; Ho, C.T.; Lai, C.S. Attenuation by Tetrahydrocurcumin of Adiposity and Hepatic Steatosis in Mice with High-Fat-Diet-Induced Obesity. J. Agric. Food Chem. 2018, 66, 12685-12695. [CrossRef] [PubMed]

24. Lai, C.-S.; Ho, C.-T.; Pan, M.-H. The Cancer Chemopreventive and Therapeutic Potential of Tetrahydrocurcumin. Biomolecules 2020, 10, 831. [CrossRef] [PubMed]

25. Srimuangwong, K.; Tocharus, C.; Tocharus, J.; Suksamrarn, A.; Chintana, P.Y. Effects of hexahydrocurcumin in combination with 5-fluorouracil on dimethylhydrazine-induced colon cancer in rats. World J. Gastroenterol. 2012, 18, 6951-6959. [CrossRef] [PubMed]

26. Moohammadaree, A.; Changtam, C.; Wicha, P.; Suksamrarn, A.; Tocharus, J.; Tocharus, C. Mechanisms of Vasorelaxation Induced by Hexahydrocurcuminin Isolated Rat Thoracic Aorta. Phytother. Res. PTR 2015, 29, 1806-1813. [CrossRef] [PubMed]

27. Kuo, C.N.; Chen, C.H.; Chen, S.N.; Huang, J.C.; Lai, L.J.; Lai, C.H.; Hung, C.H.; Lee, C.H.; Chen, C.Y. Anti-angiogenic effect of hexahydrocurcumin in rat corneal neovascularization. Int. Ophthalmol. 2018, 38, 747-756. [CrossRef]

28. Dong, H.P.; Yang, R.C.; Chunag, I.C.; Huang, L.J.; Li, H.T.; Chen, H.L.; Chen, C.Y. Inhibitory effect of hexahydrocurcumin on human platelet aggregation. Nat. Prod. Commun. 2012, 7, 883-884. [CrossRef] [PubMed]

29. Wicha, P.; Tocharus, J.; Janyou, A.; Jittiwat, J.; Chaichompoo, W.; Suksamrarn, A.; Tocharus, C. Hexahydrocurcumin alleviated blood-brain barrier dysfunction in cerebral ischemia/reperfusion rats. Pharmacol. Rep. 2020. [CrossRef]

30. Zhang, Z.; Luo, D.; Xie, J.; Lin, G.; Zhou, J.; Liu, W.; Li, H.; Yi, T.; Su, Z.; Chen, J. Octahydrocurcumin, a final hydrogenated metabolite of curcumin, possesses superior anti-tumor activity through induction of cellular apoptosis. Food Funct. 2018, 9 , 2005-2014. [CrossRef]

31. Somparn, P.; Phisalaphong, C.; Nakornchai, S.; Unchern, S.; Morales, N.P. Comparative antioxidant activities of curcumin and its demethoxy and hydrogenated derivatives. Biol. Pharm. Bull. 2007, 30, 74-78. [CrossRef]

32. Zhang, Z.-B.; Luo, D.-D.; Xie, J.-H.; Xian, Y.-F.; Lai, Z.-Q.; Liu, Y.-H.; Liu, W.-H.; Chen, J.-N.; Lai, X.-P.; Lin, Z.-X. Curcumin's metabolites, tetrahydrocurcumin and octahydrocurcumin, possess superior anti-inflammatory effects in vivo through suppression of TAK1-NF-kB pathway. Front. Pharmacol. 2018, 9, 1181. [CrossRef] [PubMed]

33. Boissy, R.E.; Sakai, C.; Zhao, H.; Kobayashi, T.; Hearing, V.J. Human tyrosinase related protein-1 (TRP-1) does not function as a DHICA oxidase activity in contrast to murine TRP-1. Exp. Dermatol. 1998, 7, 198-204. [CrossRef] [PubMed]

34. Olivares, C.; Jiménez-cervantes, C.; Lozano, J.A.; Solano, F.; García-borrón, J.C. The 5, 6-dihydroxyindole-2-carboxylic acid (DHICA) oxidase activity of human tyrosinase. Biochem. J. 2001, 354, 131-139. [CrossRef] [PubMed]

35. Trivedi, M.K.; Gangwar, M.; Mondal, S.C.; Jana, S. Protective effects of tetrahydrocurcumin (THC) on fibroblast and melanoma cell lines in vitro: It's implication for wound healing. J. Food Sci. Technol. 2017, 54, 1137-1145. [CrossRef] [PubMed]

36. Ku, B.; Kim, D.; Choi, E.-M. Tetrahydrocurcumin Inhibits $\alpha$-MSH-induced Melanogenesis via GSK3 $\beta$ Activation in B16F10 Melanoma Cells. Toxicol. Environ. Health Sci. 2019, 11, 210-218. [CrossRef]

37. Candau, D. Self-Tanning Composition Containing a Tetrahydrocurcuminoid and a Self-Tanning Agent. Google Patents, U.S. Patent 6,875,426, 2005.

38. Wolnicka-Glubisz, A.; Nogal, K.; Żąłło, A.; Płonka, P.M. Curcumin does not switch melanin synthesis towards pheomelanin in B16F10 cells. Arch. Dermatol. Res. 2015, 307, 89-98. [CrossRef]

39. Sato, K.; Toriyama, M. The inhibitory effect of non-steroidal anti-inflammatory drugs (NSAIDs) on the monophenolase and diphenolase activities of mushroom tyrosinase. Int. J. Mol. Sci. 2011, 12, 3998-4008. [CrossRef]

40. Satooka, H.; Cerda, P.; Kim, H.-J.; Wood, W.F.; Kubo, I. Effects of matsutake mushroom scent compounds on tyrosinase and murine B16-F10 melanoma cells. Biochem. Biophys. Res. Commun. 2017, 487, 840-846. [CrossRef]

41. Ali, A.; Ashraf, Z.; Kumar, N.; Rafiq, M.; Jabeen, F.; Park, J.H.; Choi, K.H.; Lee, S.; Seo, S.-Y.; Choi, E.H. Influence of plasmaactivated compounds on melanogenesis and tyrosinase activity. Sci. Rep. 2016, 6, 1-20. [CrossRef]

42. Mann, T.; Gerwat, W.; Batzer, J.; Eggers, K.; Scherner, C.; Wenck, H.; Stäb, F.; Hearing, V.J.; Röhm, K.-H.; Kolbe, L. Inhibition of Human Tyrosinase Requires Molecular Motifs Distinctively Different from Mushroom Tyrosinase. J. Investig. Dermatol. 2018, 138, 1601-1608. [CrossRef]

43. Song, T.-Y.; Chen, C.-H.; Yang, N.-C.; Fu, C.-S. The correlation of in vitro mushroom tyrosinase activity with cellular tyrosinase activity and melanin formation in melanoma cells A2058. J. Food Drug Anal. 2009, 17, 156-162. 
44. Sugumaran, M.; Barek, H. Critical analysis of the melanogenic pathway in insects and higher animals. Int. J. Mol. Sci. 2016, 17, 1753. [CrossRef] [PubMed]

45. Ancans, J.; Tobin, D.J.; Hoogduijn, M.J.; Smit, N.P.; Wakamatsu, K.; Thody, A.J. Melanosomal pH controls rate of melanogenesis, eumelanin/phaeomelanin ratio and melanosome maturation in melanocytes and melanoma cells. Exp. Cell Res. 2001, 268, 26-35. [CrossRef] [PubMed]

46. Cheli, Y. Alpha-MSH and cyclic-AMP elevating agents control melanosome pH through a PKA-independent mechanism. J. Biol. Chem. 2009, 284, 18699-18706. [CrossRef]

47. Goenka, S.; Nagabhushanam, K.; Majeed, M.; Simon, S.R. Calebin-A, a Curcuminoid Analog Inhibits $\alpha$-MSH-Induced Melanogenesis in B16F10 Mouse Melanoma Cells. Cosmetics 2019, 6, 51. [CrossRef]

48. Yoshizaki, N.; Hashizume, R.; Masaki, H. A polymethoxyflavone mixture extracted from orange peels, mainly containing nobiletin, 3, 3', 4', 5, 6, 7, 8-heptamethoxyflavone and tangeretin, suppresses melanogenesis through the acidification of cell organelles, including melanosomes. J. Dermatol. Sci. 2017, 88, 78-84. [CrossRef]

49. Al-Nasiry, S.; Geusens, N.; Hanssens, M.; Luyten, C.; Pijnenborg, R. The use of Alamar Blue assay for quantitative analysis of viability, migration and invasion of choriocarcinoma cells. Hum. Reprod. 2007, 22, 1304-1309. [CrossRef]

50. McBride, J.; Ingram, P.R.; Henriquez, F.L.; Roberts, C.W. Development of colorimetric microtiter plate assay for assessment of antimicrobials against Acanthamoeba. J. Clin. Microbiol. 2005, 43, 629-634. [CrossRef]

51. Khodashenas, S.; Khalili, S.; Moghadam, M.F. A cell ELISA based method for exosome detection in diagnostic and therapeutic applications. Biotechnol. Lett. 2019, 41, 523-531. [CrossRef]

52. Spurgers, K.B.; Hurt, C.R.; Cohen, J.W.; Eccelston, L.T.; Lind, C.M.; Lingappa, V.R.; Glass, P.J. Validation of a cell-based ELISA as a screening tool identifying anti-alphavirus small-molecule inhibitors. J. Virol. Methods 2013, 193, 226-231. [CrossRef]

53. Goenka, S.; Ceccoli, J.; Simon, S.R. Anti-melanogenic activity of ellagitannin casuarictin in B16F10 mouse melanoma cells. Nat. Prod. Res. 2019, 1-6. [CrossRef] [PubMed] 